\title{
Aportación a la obra y la estética de Eulogio Varela (1868-1955)
}

\author{
LOURDES JIMÉNEZ FERNÁNDEZ ${ }^{*}$
}

\section{RESUMEN: SUMMARY:}

La contribución de Eulogio Varela al panorama gráfico finisecular español, esencialmente desde el núcleo madrileño, es coetánea y

explicable a la recepción de los nuevos estilos el Simbolismo y su posterior versión decorativa del Ant

Nouveau. La incorporación y traducción a su producción artística de estos nuevos motivos iconográficos, lo convierten en uno de los mejores receptores de las formas modernistas en España.

Como ejemplo de ello, voy a estudiar los primeros dibujos que realizó sobre la imagineria wagneriana para Blanco y Negro, en una temática la de las óperas de Richard Wagner, que tenian en esos momentos su mayor repercusión en

la capital con el estreno de sus obras más influyentes.
By the late nineteenth-century, Eulogio's Varela works can be explained by the use of the new styles like Symbolism and its later version, the Art Nouveau. His contribution is quite remarkable in spanish graphic arts and specially in Madrid. Eulogio Varela brought in these new iconographic motives and reinterpretated them and so then he became one of the best followers of Modernism in Spain. The aim of this paper is to pointed out this hypoteses by examining Varela's first designs for "Blanco y Negro" where he uses iconographics elements from Wagner's music. The influence of Wagner on Varela's works is not strange since the first performances of Wagner's music-dramma were being succesful in the capital.

De Eulogio Varela y Sartorio (Puerto de Santa Maria, Cádiz, 18681955, Madrid), se puede afirmar sin lugar a dudas que es uno de los artistas gráficos más importantes del panorama plástico español del cruce de siglos XIX y XX. Nacido en el Puerto de Santa María no se puede hablar de él como un artista andaluz, pues su trayectoria profesional y personal están vinculadas a Madrid. Formado inicialmente en la Escuela de Bellas Artes de Valladolid, y más tarde en Madrid junto a las figuras de

* Universidad de Málaga.

** Agradezco a la Dra. Clelia Martínez Maza la traducción efectuada al inglés sobre el breve resumen introductorio; pero ante todo quiero mostrarle mi infinita gratitud por su valiosísima ayuda y amistad a pesar de las distancias. 
Alejandro Ferrant y Emilio Sala -sus maestros-, sería alli donde se dio a conocer y desarrolló su carrera como dibujante, además de obtener un importante reconocimiento profesional a través de sus ilustraciones para la revista madrileña Blanco y Negro1.

La aportación que pretendo hacer con este estudio sobre el artista portuense, es la de destacar su contribución al panorama gráfico de entresiglos convertido en uno de sus mayores representantes, así como subrayar su pronta adhesión a los nuevos estilos. Además de esto, me acercaré a los dibujos wagnerianos efectuados por Varela en los primeros años del siglo, aproximadamente 1900 -fecha de sus primeros dibujos relacionados con las noticias sobre Wagner y su música aparecidas en las páginas de Blanco y Negro- hasta 1910, año en el que podemos situar uno de los mejores dibujos wagnerianos de todos los hallados hasta ahora en el panorama gráfico español.

Aunque sus comienzos fueron los normales en la trayectoria de cualquier artista de su época, primeros contactos con el arte en las escuelas de Bellas Artes y más tarde discípulo de maestros de origen académico, en la que éstos impartían y ensayaban a su vez con el realismo anecdótico -habitual en la pintura decimonónica de la segunda mitad de siglomatizado por un factor "modernizante" de factura impresionista, que supieron incorporar y transmitir de manera subjetiva al eclecticismo pictórico del momento característico de estas fechas. Sin embargo, Varela desde un primer momento, se inicia en la adopción de los nuevos estilos -quizá aprendido en las páginas de la revista Blanco y Negro-, a la que llegó gracias a su maestro Emilio Sala, incorporándose a la plantilla de colaboradores en 1898, fecha emblemática del cambio estilístico producido en la revista hacia las formas modernistas 2.

1 La figura de Eulogio Varela aún no demasiado conocida en el panorama gráfico finisecular, cuenta ya con destacados estudios como los efectuados por BRASAS EGIDO, JOSÉ CARLOS. "Un ihstrador del Modernismo Español. Eulogio Varela y Sartorio". Goya, n's 181-182, julio-octubre, Madrid, 1984, págs. 113-116. Del mismo autor la monografía Eulogio Varela y la llustración Gráfica Modernista en Blanco y Negro. Valladolid, 1995. Asi como los estudios realizados por ARNIZ SANZ, F.M. "Eulogio Varela y los Ex Libris modernistas". Pliegos de la Academia, $n^{0} 1$, Academia de Bellas Artes de Santa Cecilia, El Puerto de Santa Maria, octubre 1991, págs. 24-27; “Eulogio Varela y las Exposiciones Nacionales de Bellas Artes". Pliegos de la Academia, $n^{\circ} 3$, Academia de Bellas Artes de Santa Cecilia, El Puerto de Santa Maria, abril 1992, págs. 4-7; y el homenaje llevado a cabo en su ciudad natal coordinada por el propio ARNIZ SANZ, F.M. Homenaje a Eulogio Varela (18681955), con motivo del XXV Aniversario de su muerte. El Puerto de Santa Maria, Fundación Municipal de Cultura del Excmo. Ayuntamiento del Puerto de Santa Maria, 1980.

2 Sus colaboraciones con la revista Blanco y Negro al principio son ocasionales, no siendo continuadas hasta 1901, fecha desde la que se constata una mayor presencia con sus caracteristicas cartelas y dibujos de indiscutible modernidad para el momento, estilo al que se mantendrá fiel durante 
Las primeras ilustraciones de Varela para Blanco y Negro se insertaban en ese realismo anecdótico presente en muchas de sus páginas desde su aparición el 10 de mayo de 1891. Ya relatada su incorporación a la revista en 1898, se puede afirmar que su presencia junto a colaboradores de esos años como José Arija y Eduardo Chiorino, seria importantísima para la nueva definición estilística de la revista hacia 19003.

1900 se convierte, por tanto, en fecha referencial por confirmarse la aceptación del estilo Art Nouveau a través de las páginas del Almanaque de 19004 ; en él coiaboraron Chiorino, Arija y el propio Varela, quienes se acercaron a las corrientes modernistas en una serie de dibujos titulada "Las flores", en la que se representaban alegorías femeninas simbolizadas con las flores características de cada estación y mes del año acompañadas por pequeños poemas, -ejemplo, Julio. "Geranios" con poesía del mismo título firmado por D. Javier de Burgos; ó el mismo mes de Agosto con dibujo de Eulogio Varela y poesía «Girasoles» de D. Joaquín Alcaide de Zafra-, motivo iconográfico que se convertiría en habitual en el modernismo - utilizando la figura femenina como alegoría relacionada con las flores-.

Estas primeras imágenes femeninas en Varela -tal y como se nos muestra en el magnífico ejemplo ya citado "Agosto: Girasoles»--, se caracterizan por su estilo posterior más representativo en una primacia del dibujo lineal, arabescos y decorativismo pleno, que a diferencia de otros

toda su trayectoria artística. Blanco y Negro cambió su imagen en 1898 con la introducción del color -peculiaridad indiscutible de su modernidad-, y la fluctuación del estilo entre un eclecticismo propio del momento con las nuevas influencias del Simbolismo y el Art Nouveau; aunque tal y como señalara FRANCESC FONTBONA, el rasgo que caracterizaría a la revista es el del realismo anecdótico enraizado en la tradición del diecinueve tardio, en "La Justración Gráfica. Las técnicas fotomecánicas", AA.VV., El Grabado en España (Siglos XIX y XX). Madrid, Summa Artis, vol. XXXII, Espasa Calpe, 1988, págs. 429-610, (pág. 484).

3 Los primeros dibujos adscritos al Simbolismo publicados en Blanco y Negro se relacionan con la figura de G. Eugenio Chiorino desde 1896. Véase como ejemplo una ilustración de 1897 titulada "Dibujos prerrafaelistas" de E. G. CHIORINO, Blanco y Negro, $n^{2} 305$, Año VII, Madrid, 6 de marzo de 1897 ó "La Natividad de Nuestra Señora". Dibujo prerrafaelista de E.G.CHIORINO, Blanco y Negro, $\mathrm{n}^{\circ}$ 332, Año VII, Madrid, 11 de septiembre de 1897.

4 Almanaque de 1900. Blanco y Negro, $n^{\circ} 452$, Madrid, 30 diciembre de 1899 . En una fecha bastante cercana a este "almanaque" la de 1904, la revista vería recompensado su esfuerzo de "renovación plástica" al obtener precisamente de uno de estos colaboradores ya mencionados JOSÉ ARIJA, una primera medalla en la Sección de Arte Decorativo de la Exposición Nacional de Bellas Artes de 1904; asi como de nuestro protagonista EULOGIO VARELA -también en esa misma exposición una segunda medalla por un cartel: «... JOSÉ ARIJA, primera medalla por un álbum en el que se incluyen más de cien dibujos publicados en esta Revista, ó fragmentos decorativos de la casa de BLANCO Y NEGRO ...". Citado por NAVARRO Y LEDESMA, F. “Especial Exposición de Bellas Artes de 1904. Pintura. Las obras premiadas". Blanco y Negro, n 685, Año 14, Madrid, 18 de junio de 1904. 
dibujantes coetáneos le lleva a rodear plenamente las viñetas, ilustraciones, poemas y críticas de las páginas de Blanco y Negro. Además de sus ilustraciones, también se pueden enumerar los diseños que realizara para orlas, grecas y viñetas, de exuberante fantasia, en los que priman la temática medieval representados por bellas doncellas medievalizantes de amplias túnicas y formas delicuescentes, caballeros, ninfas y, sobre todo, las alegorías femeninas asociadas a flores, rodeadas de cisnes, pavos reales e insertas en bellos y sombríos bosques o jardines finiseculares.

Este lenguaje de formas medievalizantes adoptado por Varela e interpretado por artistas como Chiorino, provenía fundamentalmente del prerrafaelismo inglés con una continuación posterior en los diseños de William Morris para las Arts and Crafts. Asimismo en el Simbolismo o más bien las formas popularizadas del Modernismo y más tarde en el decorativismo Art Nouveau, se recuperan también en uno de sus múltiples lenguajes plásticos y temáticos a la Edad Media, en un revival postromanticista que en el caso particular de Richard Wagner dominaba en la mayoría de sus obras, -desde el Tristán e Isolda a la histcria del caballero Tannhäuser- de ahí que tuviesen un amplio eco en ilustradores y artistas cercanos a este movimiento.

La influencia del músico y teórico alemán, supondría, por tanto, en el panorama artístico e intelectual del último tercio del siglo $X I X$, un resurgir del idealismo, de la recuperación del mito y de momentos históricos pasados, en oposición a la contemporaneidad versus positivismo-industrialismo que conllevaba la «modernidad». Será en este apartado donde se incluya a Varela en relación con la figura del músico alemán, recibiendo sus teorias y aplicándola en sus ilustraciones.

La recepción y difusión de la obra musical de Richard Wagner (18131883) en España y la trascendencia que tuvo en el panorama artístico del cruce de siglos, es un tema hasta ahora poco investigado y podemos decir que significativo en la comprensión de la recepción de la modernidad en nuestro país. La admisión de su obra teórico-musical citada por los diarios y semanarios de la época como La Música del Porvenir5, fue

5 El músico Felip Pedrell fue uno de los iniciadores de la introducción y divulgación de fragmentos musicales de sus obras en artículos publicados en el semanario artístico, literario y teatral La España Musical, aparecido en Barcelona en 1886, que se convirtio en uno de los primeros órganos de difusión de la obra wagneriana en Barcelona y por extensión al resto de España. Pedrell daría el nombre de La Música del Porvenir en los siguientes artículos: La España Musical, IV, (25-XI-1869), 1-2; (2-XII-1869), 2; (30-XI-1869), 2. Citado por JANÉS I NADAL, ALFONSINA. L'obra de Richard Wagner a Barcelona. Barcelona, Fundació Salvador Vives i Casajuana, Ajuntament de Barcelona, 1983, pág. 25. 
presentada desde la década de los ochenta con mayor insistencia. Los estrenos de sus óperas más conocidas tanto en el plano musical como plástico se producen en fechas bastante tardías. El Tristán e Isolda y La Walkiria, ambas representadas por primera vez en 1899 en el Teatro del Liceo de Barcelona y la segunda en el Teatro Real de Madrid, atraen a los sectores más renovadores en el plano musical que ansiaban ver puestas en escena las óperas del compositor, y apreciar la renovación que había llevado a cabo desde el campo operístico - la creación o más bien se podría decir la recuperación y readaptación del drama musical-, frente al tradicionalismo que suponía la ópera italiana y en especial del belcantismo (Bellini, Donizetti, Rossini), aceptado hasta esos momentos por los sectores más conservadores del público que acudia a los teatros.

En este proceso de introducción de la obra wagneriana en España en cuanto a su recepción plástica, jugaron un papel decisivo las ilustraciones y dibujos publicados en las revistas ilustradas de la época sobre la figura del compositor y sus obras, siendo de este modo una de las vías iniciales por donde se originaría la influencia wagneriana en el campo plástico 6 . Con relación al panorama gráfico madrileño y en concreto desde las páginas de Blanco y Negro, podemos afirmar que ésta comenzó a hacerse eco de noticias sobre Wagner desde sus inicios -sobre todo relativas a la actividad concertística y de la programación en las temporadas del Teatro Real de sus óperas románticas: Lohengrin, Tannhäuser...-; aunque se fechan en los años de los estrenos de sus obras más influyentes - La Walkyria (enero 1899) y Siegfried (marzo 1901)- en el mismo teatro, los primeros dibujos relacionados con el wagnerismo.

Estas primeras imágenes wagnerianas que se comenzaron a difundir en las revistas ilustradas desde la década de 1880 , sobre todo debidas a la firma de autores extranjeros -esencialmente alemanes- en revistas como La llustración Española y Americana, La llustración Ibérica ó La Ilustración Artística7, se encuadraban en un estilo ecléctico predominante en el momento. Sin embargo, se puede confirmar que un gran número

6 En concreto podemos citar los estudios efectuados sobre su repercusión en Cataluña, y más concretamente en el Modernisme por ELISEU TRENC BALLESTER. "El wagnerisme a les arts plàstiques catalanes (1880-1910)". Miscel'lània Joan Gili. Barcelona, Publicacions de I'Abadia de Montserrat, 1988, págs. 559-584; asi como los realizados por LOURDES JIMÉNEZ FERNÁNDEZ: "Escenografias wagnerianas en Cataluña: distintas propuestas formales a la introducción del wagnerismo en la "Época del Modernismo". Boletín de Arte $n^{2} 18$, Departamento de Historia del Arte, Universidad de Málaga, 1997, págs. 233-247; “Introducción de la iconografia wagneriana en la Barcelona de la Restauración (1882-1885)". Boletín de Arte $n^{\circ} 20$, Departamento de Historia del Arte, Universidad de Málaga, 1999, págs. 211-236; y especialmente "La recepció de la imatge wagneriana pels modernistes catalans". Revista de Catalunya $n^{Q} 154$. Nova Etapa, setembre de 2000 , Barcelona, Fundació Revista de Catalunya, págs. 53-74. 
de los ilustradores y dibujantes españoles interpretaron los mitos wagnerianos desde la estética simbolista y bajo las formas del Art Nouveau; esto es debido en parte a las fechas tardías en que se estrenan sus óperas más influyentes respecto a otras ciudades europeas, y el conocimiento de los nuevos estilos que ya circulaban por los ambientes artísticos más renovadores, y que se le ofrecía al artista tras su «inevitable» viaje a París -especialmente en el contexto artístico catalán-convertido en el principal receptor y difusor de las formas modernistas en España, frente al inmovilismo en las formas academicistas y eclécticas difundidas en los ambientes artísticos de la capital, y refrendados por el tradicionalismo conservadurista que se mostraba generalmente en las secciones oficiales de las Exposiciones Nacionales de Bellas Artes.

Otra vía que también llevó a nuestros artistas a entrar en contacto con la iconografía wagneriana pudo ser a través del conocimiento y aprendizaje obtenidos en las revistas ilustradas extranjeras que circulaban por el momento, como las inglesas The Studio ó The Yellow Book, la alemana Jugend y la austriaca Ver Sacrum, amén de la francesa La Plume entre otras. Característica ésta por tanto de gran trascendencia y a la que nuestros especialistas han dedicado poca atención en la llegada de nuevas corrientes e influencias externas en el Simbolismo español, especialmente en los artistas que se dedicaban, en un número mayor del que pensamos, a la ilustración de estas revistas.

La iconografía wagneriana comenzó a extenderse a través de todo tipo de impresos modernistas: carteles, postales, cromos, anuncios publicitarios, programas musicales..., para alcanzar a todos los niveles plásticos desde la pintura decorativa a la escultura, invadiéndose el panorama artístico del cruce de siglos, por toda suerte de personajes wagnerianos que convivian en absoluta armonía con otras iconografías vigentes en la época y caracteristicas del Simbolismo como las rescatadas hadas, ninfas, sirenas, esfinges, doncellas medievalizantes, caballeros legendarios, con las que entre ellos Varela ilustraban las páginas de las revistas y diarios. Esta nueva iconogratia se componia principalmente por seres miticos y de leyenda, Lohengrin, El Holandés Errante, Tristán e Isolda, Parsifal, Tannhäuser..., asi como de toda suerte de personajes fantásti-

7 Sobre las revistas ilustradas barcelonesas La llustración Artística y La llustración Ibérica y la aparición de la iconogratía wagneriana en sus páginas, remito al articulo citado en nota 6 de ELISEU TRENC BALLESTER. "El wagnerisme a les arts plàstiques...", y el de LOURDES JIMÉNEZ FERNÁNDEZ. "Introducción de la iconografía wagneriana en la Barcelona de la Restauración (1882-1885)", en los que se hace una aproximación a la reproducción de escenas wagnerianas de artistas esencialmente alemanes en las páginas de estas revistas. 
cos retomados de la leyenda nórdica -epopeya de los Nibelungos-: hijas del Rhin, enanos, gigantes, diosas y heroinas guerreras como las Walkirias, que vinieron a enriquecer el vasto panorama iconográfico del cruce de siglos español.

Ya con el comienzo del 1900, aparecen en las páginas de Blanco y Negro personajes wagnerianos con una iconografía muy determinada y bastante popular para la mayoría de lectores y espectadores que estaban informados de las novedades escénicas producidas en la capital. Desde Lohengrin, con su inconfundible figura asociada a la nave tirada por el cisne, a Brunilda, la heroína por antonomasia wagneriana, reclamaban con fuerza un lugar privilegiado en el repertorio gráfico de los mejores de nuestros caricaturistas e ilustradores. De los autores 8 que trabajan esta temática wagneriana en los primeros años del siglo (1900-1910), podemos confirmar que será Eulogio Varela el que mejor y con más asiduidad se acerque a esta iconografía.

La primera de sus ilustraciones fechada en $1900^{9}$ (Fig. 1), aunque acompañaba un artículo de nombre eminentemente wagneriano, el contenido del mismo así como los dibujos de Varela no hacían referencia alguna a la última jornada de la tetralogía wagneriana, El Oro del Rhin, La Walkyria y El Ocaso de los Dioses. El crítico Eugenio Sellés habitual de la revista, aprovecha la audición en Madrid en versión concierto -pues aún faltaban unos años para su estreno en el Teatro Real del Ocaso de los Dioses-10, para hacer una metáfora con la obra del compositor del "ocaso" que se estaba viviendo en la España de principios de siglo, tras la consabida crisis del ' 98 .

Varela en la primera página despliega una gran orla -en forma de portaestandarte11-, que enmarca el texto en su totalidad desde la izquierda y

8 Considero en este estudio únicamente la figura de Eulogio Varela, dejando para análisis posteriores la aportación de otros artistas a la iconografía wagneriana en la revista Blanco y Negro. Sí quiero destacar en este momento, la aportación de José Arija con un magnífico dibujo en la portada deł 23 de noviembre de 1901. Wotan i Brunilda. La Walkyria, en la que el artista se aproxima al lenguaje wagneriano de marcada influencia germánica en su transcripción, en uno de los ejemplos más bellos del panorama español de esta singularisima temática.

9 SELLÉS, EUGENIO. «EI Ocaso de los Dioses». Contraportada con dibujos de EULOGIO VARELA, Blanco y Negro nำ 472, 19 de mayo de 1900, Madrid, págs. 2-3.

10 Éste se realizó en la $59^{\circ}$ Temporada (1908-1909), en la que se programaron entre otras óperas de Wagner en 1908: Die Walkûre, La Walkyria, los meses de noviembre, diciembre, febrero y marzo. Siegfried, Sigfrido, entre diciembre y febrero. En 1909 Lohengrin, los meses de enero, febrero y marzo, y el estreno de Götterdämmerung, El Ocaso de los Dioses, en marzo de ese mismo año.

11 Eulogio Varela utilizaria este recurso compositivo de los "portaestandartes" en los que insertaba sus dibujos, en muchas de las composiciones que en años posteriores a la que nos ocupa he teni- 
se abre en la parte superior en una banderola con el título El Ocaso de los Dioses; mientras que en el centro de la composición sitúa de nuevo una banderola mayor, donde dispone una procesión de caballeros medievales con corazas y pajes en actitudes de derrota y abatimiento. La ilustración está inserta de pleno en las características del Art Nouveau, con el sintetismo de las formas que aparecen en el portaestandarte, así como la huella de la influencia céltica adaptada a los enganches de la banderola.

La segunda composición que forma parte del citado artículo se titulaba La aurora de los enanos. En este caso Varela vuelve a enmarcar el texto con el dibujo en el margen izquierdo de la página, aunque esta vez sea un encuadre rectangular - destacando de ella un gran tallo-, coronado por flores de corte modernista que surgen desde el nivel de la tierra de donde aparece una procesión de seres fantásticos -duendes del bosque-. De nuevo el sintetismo y las lineas curvas se subrayan por una línea gruesa que enmarca y delinea a los personajes y a la flor modernista, y los lleva a aproximarse a las características del Art Nouveau. Como comprobamos, la vinculación de los dibujos con el drama wagneriano no guardan ninguna relación, ajustándose nuestro dibujante al texto al que hacía referencia el crítico. No podemos por tanto con este ejemplo hablar de iconografía wagneriana.

Más en los primeros años del siglo, Varela retoma el tema wagneriano al ilustrar en 190412 la versión publicada sobre el Tristán e Iseulda 13 (Fig. 2), dentro de una sección dedicada a dar a conocer Cuentos fantás.

do ocasión de comprobar. Ejemplo de ello es la composición para "Ensueño» de Gregorio Martínez Sierra con ilustraciones de nuestro autor, en la que presenta dos portaestandartes muy parecidos al del ejemplo wagneriano y que guardan la misma disposición, Blanco y Negro, Madrid, $n^{0} 567,1902$

12 Recordemos el reconocimiento oficial que a su tarea de ilustrador le habia sido premiada en las Exposiciones de Bellas Artes en su sección de Arte Decorativo, con una tercera medalla en 1901 con "Dibujos y bocetos decorativos"; en las de 1904 y 1906 respectivamente con medallas de segunda clase concurriendo con "Pinturas y dibujos decorativos" y en la de 1906 con "Fiesta veneciana. Pintura decorativa", para obtener el máximo reconocimiento en 1908 con medalla de primera clase en la Sección de Arte Decorativo con un "Álbum con cien proyectos varios", en la que curiosamente también fue premiado con primera medalla un tema wagneriano efectuado por Luis García Sampedro, "Wagner, boceto de pintura mural". Citado por BERNARDINO DE PANTORBA, Historia y Crítica de las Exposiciones Nacionales de Bellas Artes celebradas en Españá. Madrid, Ediciones Alcor, 1948, págs. $170,179,189$ y 196. Véase también la reseña efectuada por la propia revista Blanco y Negro en sus páginas por NAVARRO Y LEDESMA, F. "Especial. Exposición de Bellas Artes de 1904. Pintura. Las obras premiadas", citado en nota 4.

13 WAGNER, RICHARD. "Tristan e Iseulda". Dibujo de Eulogio Varela. Número 20 de nuestro concurso de Cuentos Fantásticos. Blanco y Negro n 694, Madrid, 20 de agosto de 1904, pág. 10. También se reproduce en BRASAS EGIDO, JOSE CARLOS. Eulogio Varela y la llustración Gráfica..., fig. 78 Esta ilustración fue donada por los herederos del artista al Museo Municipal del Puerto de Santa Maria: Tristán e Isolda, ilustración para Blanco y Negro, huecograbado/papel, 0’29 × 0’39 cm. 
ticos ${ }^{14}$. La ilustración se presenta en una doble página a color, enmarcada por una composición rectangular envuelta por una línea negra que aísla el dibujo del texto y lo divide en dos mitades, recurso utilizado frecuentemente por el artista en muchas de sus ilustraciones y viñetas. En este ejemplo será la mitad superior la que cobre mayor protagonismo al situar en ella a los protagonistas del drama, Tristán e Isolda 15 frente a la mitad inferior más reducida, y que le sirve de extremo de compensación de la ilustración.

Varela se adecua al drama wagneriano recreando la escena quinta del primer acto, en el momento cumbre y muy reconocido mayoritariamente por el público -y quizá para el propio artista- de la bebida del filtro de amor por los protagonistas. La acción la sitúa correctamente a bordo de la cubierta de la nave que conduce a la princesa Isolda de Irlanda a desposarse con Marke, rey de Cornualles y guiada por Tristán -sobrino del reya quien ya una vez salvara la vida la princesa. La propia Isolda en venganza a Tristán por entregarla como esposa, ordena a su criada Brangania preparar los filtros de muerte (que más tarde cambiaría la misma en un acto de lealtad y afecto hacia su señora por los de amor), para brindárselo a éste en el momento que se le acercara, vengando así su acción y desencadenándose de esta forma, la más impetuosa y sentida de las pasiones humanas, un amor voluptuoso y sensual por encima de las leyes naturales y humanas.

Vemos en la composición que Varela recrea la escena libremente y alejado de cualquier modelo iconográfico de la época, al contrario que otros autores que basaban sus modelos en artistas alemanes; asimismo el portuense no continúa en una mera «imitatio» con los prototipos iconográficos seguidos no sólo por ilustradores, sino también por escenógrafos y figurinistas cercanos a la órbita de influencia centroeuropea y más concretamente alemana. Varela escoge y recrea independientemente-quizá sin hacer un acercamiento personal al drama wagneriano-, una escena

14 Sección que fue encargada en cuanto a su ilustración a Eulogio Varela y que comenzaría en el mismo año de 1904, entre otros ejemplos me remito además de uno de primeros de año y el de julio del Tristán e Iseulda, al aparecido en diciembre: "El Guante". Lema SULFONAL (Número 36 de nuestro concurso de Cuentos Fantásticos), con dibujos de Varela. Blanco y Negro, n 711, Año 14, Madrid, 17 de diciembre de 1904, en la que Varela vuelve a repetir el mismo esquema empleado para el ejemplo wagneriano.

15 Véase el estudio efectuado por LOURDES JIMÉNEZ FERNÁNDEZ, “Nuevos prototipos femeninos para el Cruce de Siglos (XIX-XX): de la Mujer Germánica a la Isolda wagneriana", Boletín de Arte $n^{\circ}$ 21, Departamento Historia del Arte, Universidad de Málaga, 2000, págs. 263-288, en el que se analizan en detaile los origenes de la leyenda tristanesca y su recepción crítica y plástica en los círculos simbolistas y decadentistas europeos del fin de siglo XIX. 
de ambiente medievalizante como muchas de las que ilustraban la misma revista; no por ello, se le puede reprochar su inmejorable valia y sensibilidad artística, su decorativismo y singularidad única en las ilustraciones modernistas del panorama gráfico español.

En un decorativismo recargado y quizá algo confuso nos presenta la ilustración en dos espacios bien diferenciados, la mitad superior con los personajes protagonistas Isolda-recostada en el lecho y con la copa del filtro en la mano-; Tristán asimismo con el objeto del fatal desenlace también en sus manos, y la fiel criada Brangania que se retira del escenario. La continuación de la escena viene dada por el mástil que sirve de unión entre los planos superior e inferior, en el que se sitúa un caballero -«rudo marinero"- en el texto wagneriano que conduce la nave hacia tierras de Cornualles.

Todos los personajes responden a un modelo iconográfico -de caballeros y damas medievalizantes-, codificado y repetido por Varela para sus múltiples composiciones de temática medieval que ilustraban las páginas del Blanco y Negro. Nos presenta a una Isolda 16 , prototipo iconográfico femenino de mujer de belleza fría y algo estática, características repetidas en la larga nómina de féminas ambientadas en el medievo, de túnicas vaporosas y llenas de sensualidad típicas del autor. Isolda se presenta con túnica blanca, tocado renacentista y recostada en el lecho, en una posición de altivez frente a su antagonista masculino, el caballero Tristán. Éste a su vez y fuera de toda duda, también responde a los prototipos masculinos de estilo medievalizante caracterizados por el autor; podemos comparar perfectamente su imagen -así como la del marinero que en el extremo inferior conduce el timón del navio-, con la primera ilustración ya comentada sobre los caballeros del artículo El Ocaso de los Dioses. Figuras jóvenes, de belleza no demasiado viril, delicados y frágiles caballeros -más poéticos que aguerridos guerreros- pueblan sus composiciones, vestidos con mallas y túnicas bordadas, o con armaduras llenas de filigranas, en un decorativismo ejemplar que responde a una estética heredada del prerrafaelismo y la iconografia que popularizara parte del mundo de ensoñación y fantasía del simbolismo finisecular.

La composición se inserta de pleno en el estilo modernista, con caracteres célticos y un decorativismo exaltado y acentuado que llega a extremos barroquizantes, como en el detallismo del mástil y parte de la proa del barco, componiendo una escena un tanto confusa. El texto que acom-

16 Véase JIMÉNEZ FERNÁNDEZ, LOURDES. "Nuevos prototipos femeninos"..., págs. 273-284. 
paña la composición de Varela, aunque aparece firmada por el propio compositor -Wagner-, se trata de una versión "libre» del drama compuesto por éste basado en las leyendas de Beroux y Thomas.

Antes de pasar a la última escena referente a la Wagneriana del poeta modernista Rubén Darío, hagamos referencia al principal exponente europeo -más concretamente parisino-, en la acogida y difusión de Richard Wagner en el último tercio del siglo XIX y que nos sirve para enlazar y contextualizar la última de las imágenes wagnerianas estudiadas de Varela.

Podemos afirmar sin lugar a dudas, que el poeta francés Charles Baudelaire (1821-1867) fue el gran iniciador de esta fiebre wagneriana en Europa, me refiero con ello por supuesto fuera del campo musical -excluyendo por tanto a eruditos y críticos musicólogos, etc.-, teniendo en España también una impronta bastante importante. Baudelaire se convierte por tanto en un ferviente wagneriano17, además de crear una expectación algo inusual hasta la fecha -en el panorama artístico e intelectual de su tiempo- por la obra de un músico, incluyéndose por tanto también a Richard Wagner en este contexto artístico como un indiscutible padre de la modernidad artística junto al poeta francés.

Baudelaire ya había anunciado la "muerte del cisne»-crisis y decadencia del fin de siglo- por los boulevares parisinos 18 , sin embargo el otro de los poetas modernistas por excelencia, el nicaragüense Rubén Darío (1867-1916) -figura clave del Modernismo literario español- recurre de nuevo a la figura del cisne, símbolo utilizado tanto en poesía como en las artes del momento y particularmente en el modernismo. El cisne de Darío se convierte en este ejemplo, en el Cisne wagneriano de la resurrección del género humano en una vuelta al mundo del ideal.

17 Es bastante conocida la adscripción a la obra teórica y musical wagneriana por parte del poeta francés, sobre todo después de la audición de fragmentos de su ópera Tannhäuser en París, 1861. Ver sus escritos: "Lettre de Baudelaire a Wagner". Viernes, 17 de febrero de 1860, y "Richard Wagner et Tannhäuser à Paris". Revue Européenne, 1 de abril de 1861, reproducidos en BAUDELAIRE, CHARLES. El arte romántico, Madrid, Ed. Felrnar, 1977, págs. 255-263.

18 ". Vi a un cisne que se habia fugado de su jaula./ Rozando el empedrado con sus palmeadas patas, / Sobre el áspero suelo arrastraba el plumaje/ Y sumergía las alas neniosas en el polvo,/Con el pico sediento, junto a un arroyo seco,/ Diciendo con nostalgia de su lago natal:/ “ ¿Cuándo caerás, lluvia?" "Rayo, ¿cuándo tú trueno?"/Veo a este desgraciado, mito fatal y extraño.../...Asi, frente a este Louvre, una imagen me asalta/ $Y$ pienso en mi gran cisne, con sus gestos dementes, /Como los exiliados, ridiculo y sublime,/ „Roido de un deseo sin tregua!... BAUDELAIRE, CHARLES. "El Cisne". A Víctor Hugo, poema perteneciente a "Cuadros Parisienses", forma parte de Las Flores del Mal. Madrid, Alianza Editorial, 1977, $2^{a}$ reimpresión 1987. Traducción de Antonio Martínez Sarrión, págs. 115-117- 
"Fue en una hora divina para el género humano.

El Cisne antes cantaba sólo para morir.

Cuando se oyó el acento del Cisne wagneriano

Fue en medio de una aurora, fue para revivir...19

No olvidemos que el cisne aparece en dos de las obras del músico alemán como Lohengrin y Parsifal asociándose desde su difusión inseparablemente a la iconografía wagneriana, particularmente con la del caballero Lohengrin conducido por un cisne desde la región de Montsalvat en ayuda de la joven Elsa von Brabante. Pues bien, Dario en su serie Wagneriana. Lohengrin y Parsifal, publicada en Blanco y Negro, así como nuestro ilustrador Eulogio Varela 20 (Fig. 3) que hace una traducción magistral de los poemas de Dario, ambos incluyen al cisne como elemento iconográfico wagneriano.

\section{WAGNERIANA 21}

\section{Lohengrin A Enrique Prins}

"Castillo que decoras la ribera,/ boscaje que decoras el castillo,/ paloma que estremeces al tomillo,/ onda que vas por la corriente fiera,/ espuma virginal, brisa ligera,/aria de trovador, cantar sencillo,/ estrella que en el agua hundes tu brillo,/Loreley de la verde cabellera;/ cisne de nieve, pájaro sagrado,/ esquife del celeste enamorado,/ barca del joven dios, lirio del Rhin:/ de las trompetas el vibrante coro/ anuncia el casco de diamante y oro/ del bello caballero Lohengrin".

19 RUBÉN DARIOO. "El Cisne". A Ch. del Gouffre en Poesias Completas, edición, introducción y notas de Alfonso Méndez Plancarte, Madrid, Ed. Aguilar, 1967, 10² ed., págs. 587-588. Véase también la referencia que realizó sobre este poema de Dario, GIOVANNI ALLEGRA. "Sobre la fortuna de Wagner en la España modernista: Los estudios críticos de primeros de siglo", Actas del VIII Congreso de la Asociación Internacional de Hispanistas, vol. 1, 22-27 de agosto de 1983, Madrid, Ed. istmo, 1986, págs. 129-139, (pág. 129).

20 RUBÉN DARÍO. "Wagneriana». Orla de EULOGIO VARELA para ilustrar dos poemas "Lohengrin y Parsifal”, del poeta modernista, publicada en Blanco y Negro n 986, Madrid, 26 de marzo de 1910. Agradezco al Dr. Francesc Fontbona que me facilitara su reproducción original de las páginas de Blanco y Negro, asi como todos los consejos ofrecidos en este estudio. Reproducido también por BRASAS EGIDO, JOSÉ CARLOS. Eulogio Varela y la llustración Gráfica..., fig. 75. No será ésta la única ilustración que aportará Varela para poemas de Darío, como ejemplo cito el dibujo ilustrativo anterior a los poemas wagnerianos de los "Cantos de Esperanza", de RUBÉN DARÍo, dibujos de Eulogio Varela. Blanco y Negro, $n^{\circledR} 736$, Año XV, Madrid, 10 de junio de 1905.

21 Sigo la transcripción de los sonetos que fueron publicados en el número de Blanco y Negro antes citado. Véase nota anterior. Los poemas también están reproducidos en DARIÓ, RUBÉN. WAGNERIANA.: 1. "Lohengrin". Para Enrique Prins. II.- "Parsifal”. Para Guillermo Rojo (¿1893?), dentro del ciclo Bajo el Sol Argentino (1893-1898), en Poesías Completas, op. cit., págs. 963-964. 


\section{Parsifal A Guillermo Rojo}

"Violines de los ángeles divinos,/ sones de las sagradas catedrales,/ incensarios en que arden nuestros males,/ sacrificio inmortal de hostias y vinos;/ túnica de los más cándidos linos, / para cubrir á niños virginales,/ cáliz de oro, mágicos cristales,/ coros llenos de rezos y de trinos;/ bandera del cordero, azul y blanca,/ tallo de amor de donde el lirio arranca,/ rosa sacra y sin par del santo Graal:/ imirad que pasa el rubio caballero;/ mirad que pasa silencioso y fiero/ el loco luminoso Parsifal!».

Varela hace una traducción gráfica perfecta y admirable de la iconografía wagneriana, así como del sentido poético de Rubén Dario, cumpliendo de esta manera con una de las máximas de la teoría wagneriana la interrelación entre las artes -en este caso imagen y poesía-. En la composición y a diferencia con las estudiadas en otros ejemplos de nuestro dibujante, éste se acerca de lleno a la influencia iconográfica y estilistica de los ilustradores alemanes y en particular de Franz Stassen (1869-1949) 22. En este ejemplo Varela rodea totalmente al texto con el dibujo -efectuado en tinta negra-, en una orla que representa una exaltación del grafismo Art Nouveau, convirtiéndose en uno de los ejemplos wagnerianos más delicados y preciosistas hallados en el panorama artístico español.

El poema sobre Lohengrin ocupa la parte superior de la orla decorativa, destacando en el margen derecho la figura gallarda y majestuosa del caballero con sus atributos característicos: casco con figura de cisne, ropajes acordes con su categoría de caballero, espada y trompeta de oro al costado, montado sobre un esbelto y augusto cisne, navegando por lo que se supone que es la ribera de un río. Centrando los poemas a la altura de la figura de Lohengrin, aparece el castillo que enuncia Dario, y a su izquierda la figura de una ninfa -o quizá y siguiendo el texto, la de Lorelei23-, que se presenta situada delante de una roca con larga cabellera

22 FRANZ STASSEN (Hanau 1869- Berlin 1949), se le puede considerar como uno de los ilustradores wagnerianos alemanes por excelencia, debido al gran número de publicaciones sobre las obras del músico y atenerse a los cánones iconográficos "impuestos" desde la órbita de Bayreuth y la imagineria que se producia a través de los Festivales wagnerianos. Por mucho tiempo, éste va a representar la plástica wagneriana en la que varió desde las primeras ilustraciones de marcado acento Art Nouveau, a una tendencia al realismo y la grandilocuencia que promulgaban los Festivales des. de la segunda década del siglo XX. Su concepción de las obras wagnerianas fue muy difundida en la época a través de álbumes de ilustraciones de las óperas más representativas: Parsifal, Tristán e Isolda, La Walkiria...; postales, carteles, exlibris...

23 Figura creada por CLEMENS BRENTANO en su balada del mismo nombre Lorelei, e incluida en la novela Godwi (1801). Ésta servirá de modelo para versiones posteriores que casi la atribuían como 
de grafías modernistas, semidesnuda, de curvas indolentes y sensualidad extremas. La túnica que le cubre la mitad de su cuerpo, se enlaza con la mitad inferior de la orla en su margen izquierdo conectando con la figura del héroe Parsifal, reconocible en su actitud de abatimiento y la aureola nimbada sobre su cabeza en lucha constante por alcanzar el Santo Grial.

En la parte inferior de la composición, Varela continúa ofreciéndonos una fiel traducción del poema de Rubén Darío, Parsifal, situando en la composición de izquierda a derecha de éste - su figura abatida, vestido con ropas y atributos medievales y una túnica que se enlaza con la figura femenina-, aunque la de nuestro héroe se acompaña por adornos de cruces en alusión al drama wagneriano. Además de Parsifal como figura principal, le acompaña en un plano inferior la figura de otro caballero que porta un incensario del que sobresalen unas líneas onduladas y sinuosas, que llevan a envolver a todas las figuras de la ilustración. A la derecha de la misma y cerrándola a su vez, aparece la personificación de un ángel -casi no se distingue su naturaleza sexual-, arrodillado y portando la copa del Santo Grial entre sus manos.

Para finalizar se podría señalar que de los dibujos analizados hasta ahora del artista portuense, quizá sea este último el que se adecue de una forma modélica a la iconografía wagneriana, realizando un estudio mucho más detenido -no ya de los dramas wagnerianos Lohengrin o Parsifat, sino de lo que es mucho más relevante de los poemas de Darío en una conjunción paradigmática en el modernismo español de literatura e ilustración. La aportación que hago a la figura de Eulogio Varela queda por tanto confirmada en este estudio, en el que además de subrayar su importante contribución al mundo gráfico del cruce de siglos, se destaca como un buen representante de la incorporación y traducción de la imaginería wagneriana que abarcaría los primeros años del siglo XX en España, insistiendo en su particular tributo a esta temática, la wagneriana, de singular repercusión en el modernismo plástico internacional.

una antigua leyenda. Básicamente su figura era la de una joven enamorada que destrozada por la infidelidad de su amante, se venga del género masculino atrayéndolos desde lo alto de una roca situada en el Rhin. Conocerá múltiples variantes y lecturas, aunque casi siempre aparece como una figura femenina - maga, hechicera, ninfa, diosa de las aguas, sirena, hada...-. Entre otros autores literarios nos encontramos con las versiones de Heinrich Heine (Lorelei, poema, 1823); Gerard de Nerval (Loreley, souvenirs d'Allemagne, 1852); Jean Lorrain (Loreley, 1897); c las más tardias como el poema de Guillaume Apollinaire (La Loreley, 1904), entre los más destacados. 


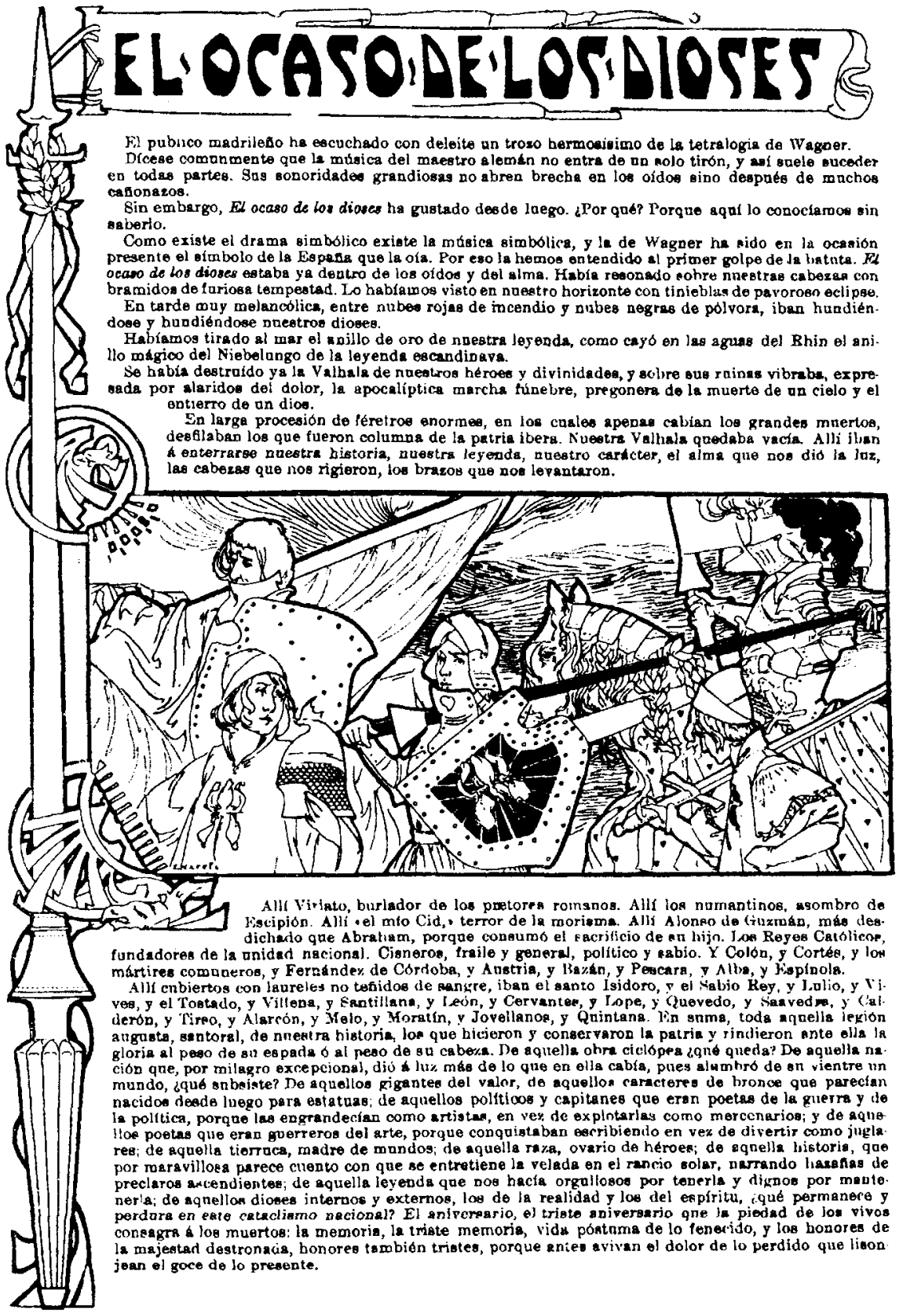

Fig. 1. "El Ocaso de los Dioses". Dibujo de Eulogio Varela, Blanco y Negro $n^{\circ}$ 472, Madrid, 19 de mayo de 1900, pág. 2. 


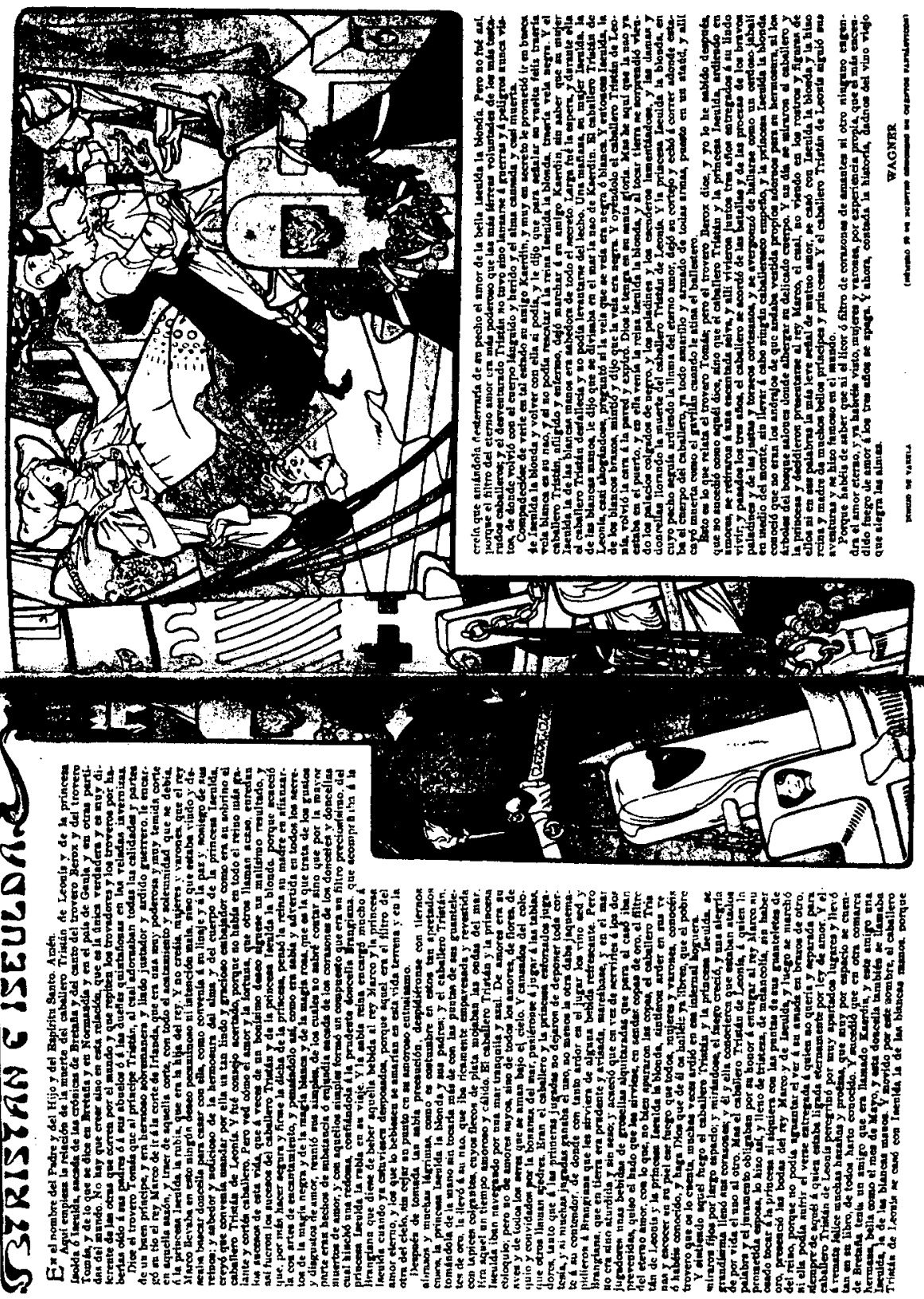

Fig. 2. "Tristán e Iseulda". Dibujo de Eulogio Varela, Blanco y Negro, Madrid, 20 de agosto de 1904, pág. 10. 


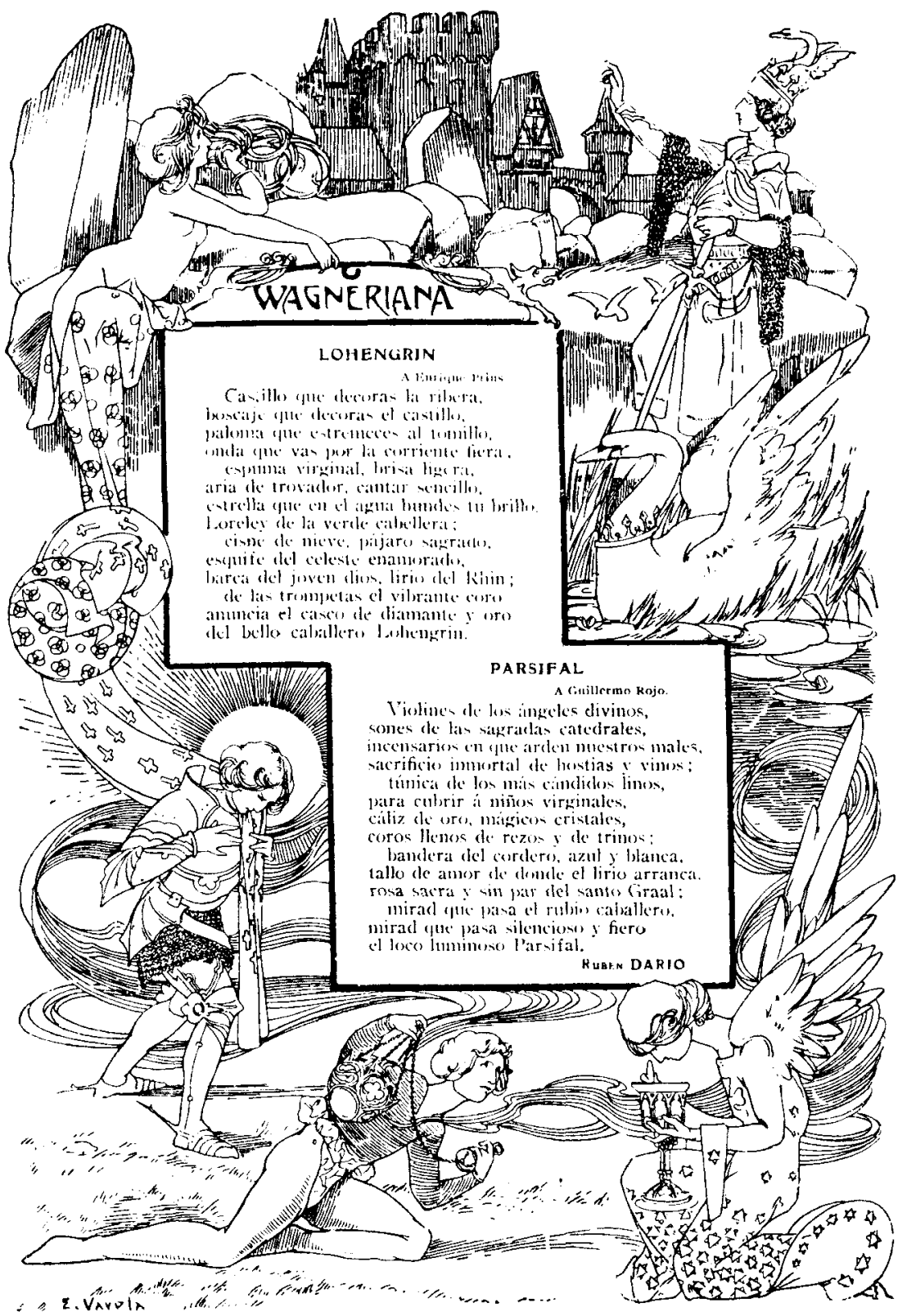

Fig. 3. RUBÉN DARIO "Wagneriana. Lohengrin y Parsifal". Dibujo de Eulogio Varela, Blanco y Negro, Madrid, 26 de marzo de 1910. 
